\title{
Comparison of capecitabine and 5-fluorouracil in chemoradiotherapy for locally advanced pancreatic cancer
}

Yeon-Joo Kim ${ }^{\dagger}$, Woo Jin Lee ${ }^{\dagger}$, Sang Myung Woo ${ }^{\dagger}$, Tae Hyun Kim${ }^{*}$, Sung-Sik Han, Bo Hyun Kim, Sung Ho Moon, Sang Soo Kim, Young Hwan Koh, Sang-Jae Park, Joo-Young Kim, Dae Yong Kim and Joong-Won Park

\begin{abstract}
Background: Although capecitabine has theoretical advantages in the pharmacokinetics, such as higher intratumoral and lower systemic concentration, relative to bolus 5-fluorouracil (5-FU), outcomes of chemoradiotherapy (CRT) with capecitabine or bolus 5-FU have not been directly compared in patients with locally advanced pancreatic cancer. Therefore, we retrospectively compared the outcomes, including toxicity, tumor response, and overall survival, of oral capecitabine plus radiotherapy (RT) with bolus 5-FU plus RT, in patients with locally advanced pancreatic cancer.

Methods: Between August 2006 and January 2012, 98 patients with locally advanced pancreatic cancer received CRT, with 52 receiving concurrent oral capecitabine and 46 receiving bolus injection of 5-FU. Primary tumor and overall response after CRT were evaluated radiologically, and toxicity, tumor response, and overall survival (OS) were compared in the two groups.

Results: Baseline clinical parameters of the two groups were similar. The rates of $\geq$ Grade 3 hematologic ( $0 \%$ vs. $8.7 \%, p=0.045)$ and non-hematologic ( $0 \%$ vs. $8.7 \%, p=0.045$ ) toxicities were significantly lower in the capecitabine group than in the 5 -FU group. Primary tumor (30.7\% vs. $28.2 \%, p=0.658)$ and overall $(13.7 \%$ vs. $15.2 \%, p=0.273)$ response rates and median OS time $(12.5$ months vs. 11.6 months, $p=0.655)$ were similar in the two groups.

Conclusions: Capecitabine plus RT may be a safe and feasible regimen for patients with locally advanced pancreatic cancer, with similar efficacy and low rates of toxicities compared with bolus 5-FU plus RT.
\end{abstract}

Keywords: Pancreatic cancer, Chemoradiotherapy, 5-Fluorouracil, Capecitabine

\section{Introduction}

Surgical resection is the only curative treatment for pancreatic cancer, but only $10-15 \%$ of patients have localized and resectable disease at diagnosis. Approximately $50 \%$ of pancreatic cancer patients present with distant metastatic disease and 30\% present with localized and unresectable disease. The Gastrointestinal Tumor Study Group (GITSG) trials [1-3] showed that chemoradiotherapy (CRT) with bolus injection of 5-fluorouracil (5-FU) yielded a modest survival benefit when compared with radiotherapy (RT) or chemotherapy alone. Since then, CRT plus bolus 5-FU has

\footnotetext{
* Correspondence: k2onco@naver.com

${ }^{\dagger}$ Equal contributors

Center for Liver Cancer, Research Institute and Hospital, National Cancer

Center, Goyang, Republic of Korea
}

been regarded as a standard therapy for patients with locally advanced pancreatic cancer. Despite recent advances in diagnostics and therapeutics, the prognosis of patients with locally advanced pancreatic cancer has remained poor, due to high rates of local progression and distant metastasis. Thus, various chemotherapeutic regimens, with various dosages and schedules and with or without RT, have been tested to improve survival [4-8].

Capecitabine, an oral prodrug of 5-FU, is absorbed by the gastrointestinal tract and metabolized to 5 -FU by a cascade of three enzymes. Capecitabine is converted by carboxylesterase in the liver to $5^{\prime}$-deoxy-5-fluorocytidine ( $5^{\prime}$-DFCR), by cytidine deaminase in the liver and tumor tissue to $5^{\prime}$-deoxy-5-fluorouridine (5'-DFUR), and by thymidine phosphorylase (TP) to 5-FU in tumor tissue. 
TP is more concentrated in tumor tissue than in normal tissue, and is upregulated by radiation in tumor tissue but not in normal tissue. Thus, oral capecitabine can result in a higher intratumoral and lower systemic 5-FU concentration than bolus 5-FU $[9,10]$. This improved therapeutic index, along with more favorable pharmacokinetics (similar to those of protracted infusion of 5-FU), and convenient oral administration without the need for central venous access and an ambulatory infusion pump, make capecitabine particularly appealing to use in conjunction with RT. To our knowledge, however, outcomes of CRT with capecitabine or bolus 5-FU have not been directly compared in patients with locally advanced pancreatic cancer. We therefore retrospectively compared the outcomes, including toxicity, tumor response, and overall survival, of oral capecitabine plus RT with bolus 5-FU plus RT, in patients with locally advanced pancreatic cancer.

\section{Methods \\ Patients}

Between August 2006 and January 2012, 52 patients with primary locally advanced pancreatic cancer underwent CRT with capecitabine under a phase II protocol. Eligibility criteria included: (1) pathologically confirmed pancreatic carcinoma; (2) unresectable disease (stage cT4) on computed tomography (CT)/positron-emission tomography (PET); (3) radiographically assessable disease; (4) age $\geq 18$ years; (5) performance status of 0 to 1 on the Eastern Cooperative Oncology Group (ECOG) score; (6) adequate bone marrow (white blood cell count $\geq$ $2,000 / \mathrm{mm}^{3}$, hemoglobin $\geq 7.5 \mathrm{~g} / \mathrm{dL}$, platelet count $\geq$ $100,000 / \mathrm{mm}^{3}$ ), liver (total bilirubin $\leq 3.0 \mathrm{mg} / \mathrm{dL}$ ), and renal (serum creatinine $\leq 1.5 \mathrm{mg} / \mathrm{dL}$ ) function; and (7) oral intake (including J-tube feeding) of $\geq 1,500$ calories/ day. Patients with elevated bilirubin due to obstruction were stented and their bilirubin decreased to $\leq 3.0 \mathrm{mg} /$ $\mathrm{dL}$, and patients with biliary or gastroduodenal obstruction underwent drainage prior to study entry. Exclusion criteria included: (1) radiographic evidence of metastasis in the major viscera or peritoneal seeding on CT and/or PET; (2) previous history of RT adjacent to the planned field; (3) pregnancy or breast feeding; and (4) previous history of uncontrolled other malignancies within 2 years. All patients provided written informed consent before study enrollment and this trial was registered at clinicaltrials.gov (NCT00658840).

During the same study period, 46 patients who refused to participate in this protocol received CRT plus 5-FU, the routine clinical practice regimen in our institution for patients with locally advanced pancreatic cancer. This study was conducted in accordance with the guidelines of the institutional review boards of the National Cancer Center.
Before CRT, patients were given physical examinations and underwent blood tests, including complete blood count, liver function tests, and serum CA 19-9 concentrations; chest radiography, and dynamic CT and/or PET of the abdomen and pelvis. All tumors were staged using the American Joint Committee on Cancer (AJCC), $6^{\text {th }}$ edition, and were classified as stage cT4 (unresectable disease), based on the CT scans, with tumor extension to the celiac axis or superior mesenteric artery or occlusion of the superior mesenteric-portal venous confluence. Primary tumors were measured bi-dimensionally, with lymph node involvement defined by the presence of a lymph node $\geq 1 \mathrm{~cm}$ in the short-axis, with a spiculated or indistinct border, or with a mottled heterogeneous pattern on CT with or without PET $(\mathrm{n}=87)$ [11]. Table 1 shows the baseline patient characteristics.

\section{Treatment}

\section{Radiotherapy}

Prior to RT, all patients underwent CT simulation, with their targets defined in accordance with the International Commission on Radiation Units and Measurements Report 50. The gross tumor volume (GTV) encompassed the gross tumor, as defined by contrast CT or PET scan. The clinical target volume (CTV) included the GTV and the volumes of regional lymph nodes, including the porta hepatic, pericholedochal, celiac, and pancreaticoduodenal nodes. The initial and boot planning target volume (PTV) included the CTV and GTV plus a 5-10 $\mathrm{mm}$ margin. All patients underwent threedimensional treatment planning, such that the PTV would be encompassed by a $90 \%$ isodose volume of the prescribed dose.

An initial dose of 45 Gy in 25 fractions was delivered to the primary tumor and regional lymph nodes, followed by a boost of 10.8 Gy in 6 fractions to the gross tumor, 5 days a week. All patients received a total radiation dose of $55.8 \mathrm{~Gy}$ in 31 fractions.

\section{Chemotherapy}

Capecitabine or 5-FU was delivered concurrently with $\mathrm{RT}$. The capecitabine group received an oral dose of $800 \mathrm{mg} / \mathrm{m}^{2}$ twice daily for the duration of RT with weekend breaks. The 5-FU group received two cycles of intravenous bolus injection of 5 -FU $\left(400 \mathrm{mg} / \mathrm{m}^{2} / \mathrm{d}\right)$ for 3 days in the first and fifth weeks of RT.

\section{Treatment after CRT and evaluation}

Following completion of CRT, patients were evaluated clinically and underwent CT scans of the abdomen, chest radiography, and serum CA 19-9 measurements to determine tumor response and resectability. Patients who had resectable disease after CRT was considered for surgical resection, whereas patients who still had unresectable disease were 
Table 1 Patient characteristics

\begin{tabular}{|c|c|c|c|c|}
\hline Characteristic & & Capecitabine ( $n=52), n(\%)$ & 5 -FU (n = 46), n (\%) & $p$-value \\
\hline \multirow[t]{2}{*}{ Gender } & Male & $32(61.5)$ & $31(67.4)$ & $0.173^{+}$ \\
\hline & Female & $20(38.5)$ & $15(32.6)$ & \\
\hline \multirow[t]{4}{*}{ Age (years) } & Median (range) & $63(36-77)$ & $66(41-80)$ & $0.126^{\ddagger}$ \\
\hline & Mean \pm SE & $62.1 \pm 1.3$ & $65.0 \pm 1.4$ & \\
\hline & $<65$ & $31(59.6)$ & $19(41.3)$ & $0.105^{\dagger}$ \\
\hline & $\geq 65$ & $21(40.4)$ & $27(58.7)$ & \\
\hline \multirow[t]{2}{*}{ Tumor location } & Head & $30(57.7)$ & $30(65.2)$ & $0.445^{\dagger}$ \\
\hline & Body/tail & $22(42.3)$ & $16(34.8)$ & \\
\hline \multirow[t]{4}{*}{ Tumor size $^{*}(\mathrm{~cm})$} & Median (range) & $3.8(2.4-7.4)$ & $3.9(2.5-10)$ & $0.297^{\ddagger}$ \\
\hline & Mean \pm SE & $4.0 \pm 0.1$ & $4.3 \pm 0.2$ & \\
\hline & $<4$ & $28(53.8)$ & $23(50)$ & $0.840^{\ddagger}$ \\
\hline & $\geq 4$ & $24(46.2)$ & $23(50)$ & \\
\hline \multirow[t]{3}{*}{ Histological differentiation } & Well/moderate & $13(25)$ & $12(26.1)$ & $0.617^{\dagger}$ \\
\hline & Poor & $2(3.9)$ & $4(8.7)$ & \\
\hline & Not specified & $37(71.1)$ & $20(65.2)$ & \\
\hline \multirow[t]{2}{*}{$\mathrm{cN}$ classification } & No & $32(61.5)$ & $25(54.3)$ & $0.471^{\dagger}$ \\
\hline & N1 & $20(38.5)$ & $21(45.7)$ & \\
\hline \multirow[t]{4}{*}{$\overline{C E A}(\mathrm{ng} / \mathrm{mL})$} & Median (range) & $4.2(1.2-31.9)$ & $3.8(1.0-56.1)$ & $0.493^{\ddagger}$ \\
\hline & Mean \pm SE & $6.4 \pm 0.9$ & $7.7 \pm 1.7$ & \\
\hline & $<5$ & 31 (59.6) & $29(63.0)$ & $0.836^{\dagger}$ \\
\hline & $\geq 5$ & $21(40.6)$ & $17(37.0)$ & \\
\hline \multirow[t]{4}{*}{ Pretreatment CA 19-9 level (U/mL) } & Median (range) & $218.5(5.0-11445)$ & $191.5(5.0-4150)$ & $0.056^{\ddagger}$ \\
\hline & Mean \pm SE & $1179.6 \pm 307.3$ & $531.1 \pm 130.6$ & \\
\hline & $<400$ & $29(55.8)$ & $31(67.4)$ & $0.300^{+}$ \\
\hline & $\geq 400$ & $23(44.2)$ & $15(32.6)$ & \\
\hline
\end{tabular}

Abbreviations: FU fluorouracil, SE standard error, CEA carcinoembryonic antigen, CA 19-9 carbohydrate antigen 19-9, CRT chemoradiotherapy.

*Maximum diameter of the primary tumor.

${ }^{\dagger}$ Fisher's exact test, two-tailed.

${ }^{*}$ t-test, two-tailed.

considered for gemcitabine based chemotherapy (1000 mg/ $\mathrm{m}^{2}$ over 30 minutes intravenously once weekly for 3 of every 4 weeks). Patients who refused further chemotherapy or had poor performance status received supportive care.

Serum samples for measurement of CA 19-9 were obtained from all patients within 2 weeks of the initiation of CRT (pre-treatment level) and 1 month after CRT (post-treatment level). The percent decrease in CA 19-9 concentration was calculated as: CA 19-9 percent decrease $(\%)=[($ pre-treatment CA 19-9 - posttreatment CA 19-9)/pre-treatment CA 19-9] $\times 100$. Tumor responses were determined by comparison of $\mathrm{CT}$ scans taken before and 1 month after CRT using the Response Evaluation Criteria in Solid Tumors guidelines [12]. A complete response (CR) was defined as the disappearance of the primary tumor. A partial response (PR) was defined as $\geq 30 \%$ reduction in the longest diameter of the primary tumor. Progressive disease (PD) was defined as a $\geq 20 \%$ increase in the longest diameter of the primary tumor or the appearance of one or more new lesions. Stable disease (SD) was defined as a response that did not qualify as a PR or a PD. Objective response rates were calculated as the rate of $\mathrm{CR}+\mathrm{PR}$. Patients with CR or PR were considered "Responders", and those with SD or PD were considered "Non-responders". Toxicity was recorded according to the National Cancer Institute Common Terminology Criteria for Adverse Events, version 3.0. Due to difficulties in accurately scoring lower grades of acute toxicity in patients with pancreatic cancer, only grade 3 or higher acute toxicities are compared.

\section{Follow-up and statistical analysis}

After completion of treatment, patients were given follow-up examinations every 2-4 weeks for the first 3 months, and then every 3 months. For most patients, follow-up evaluations at each visit included a physical examination, complete blood count, liver function test, 
serum CA 19-9 measurement, chest radiography, and dynamic CT scan of the abdomen and pelvis. Recurrence was proven by biopsy or cytology, and/or by radiological findings that indicated an increase in tumor size.

A pretreatment serum CA 19-9 of $400 \mathrm{U} / \mathrm{mL}$, the significant cutoff point in our previous reports [13,14], or a $40 \%$ decrease in CA 19-9, close to the median value for each group, was chosen as a cutoff point for comparison of patient survival rates. Parameters in the capecitabine and 5-FU groups were compared using chisquare tests, Fisher's exact tests, and t-tests, as applicable. Overall survival (OS) was defined as the interval from the commencement of CRT to the date of death or last follow-up and its probability was calculated by the Kaplan-Meier method. Univariate and multivariate analyses were performed using the log rank test and Cox's proportional hazard model, respectively, to evaluate prognostic factors associated with OS. All statistical tests were two-sided and were performed using STATA software (ver. 9.0; Stata Corp., College Station, TX). $P$ values less than 0.05 were considered statistically significant.

\section{Results}

\section{Patient characteristics}

The clinical parameters of the capecitabine and 5-FU groups were similar (Table 2). The median follow-up time for all patients was 12.3 months (range, 2.365.8 months) and was similar in the capecitabine and 5FU groups [12.6 months (range, 2.3-39.2 months) vs. 11.2 months (range, 4.6-65.8 months), $p=0.837$ ].

\section{Toxicity}

Treatment was well tolerated in both groups and there were no treatment-related deaths. The details of the distribution of toxicities between the capecitabine and 5FU groups are summarized in Table 2. None of the patients in the capecitabine group developed Grade $\geq 3$ toxicities, whereas 4 patients each $(8.7 \%)$ in the 5 -FU group developed Grade $\geq 3$ hematologic and nonhematologic toxicities ( $p=0.045$ each).

\section{Tumor response and overall survival}

Overall and primary tumor responses were evaluated one month after CRT by imaging modalities, except in one patient who had no available radiologic images after CRT. No patient in either group achieved a CR in primary tumor or overall response. Primary tumor response was as follows: PR in 29 patients (29.9\%), SD in 67 (69.1\%), and PD in 1(1.0\%). Overall tumor response was as follows: PR in 14 patients (14.4\%), SD in 25 (25.8\%), and $\mathrm{PD}$ in 58 (59.8\%). Of the 58 patients with overall tumor responses of PD, 57 (83.6\%) had distant metastases, regardless of primary tumor response (i.e., 15 had primary tumor responses of $\mathrm{PR}$ and 42 of SD); one patient (1\%) showed primary tumor progression without distant metastasis. Overall and primary tumor responses and percent decreases in CA 19-9 concentrations in the capecitabine and 5-FU groups are summarized in Table 3. None of these between group differences was statistically significant ( $p>0.05$ each). Of the 98 patients, 7 (7.1\%) underwent surgical resection, with 5 being margin

Table 2 Comparison of toxicities ${ }^{*}$ between the capecitabine and 5-fluorouracil (5-FU) groups

\begin{tabular}{|c|c|c|c|c|c|c|c|c|c|}
\hline \multirow[b]{2}{*}{ Type of toxic effect } & \multicolumn{4}{|c|}{ Capecitabine $(n=52), n$} & \multicolumn{4}{|c|}{$5-F U(n=46), n$} & \multirow[b]{2}{*}{ p-valuet } \\
\hline & Grade 1 & Grade 2 & Grade 3 & $\overline{\text { Grade } 4}$ & Grade 1 & Grade 2 & Grade 3 & $\overline{\text { Grade } 4}$ & \\
\hline \multicolumn{10}{|l|}{ Hematologic toxicity } \\
\hline Leukopenia & 22 & 8 & 0 & 0 & 6 & 9 & 1 & 1 & 0.007 \\
\hline Anemia & 36 & 1 & 0 & 0 & 23 & 7 & 2 & 0 & 0.022 \\
\hline Thrombocytopenia & 18 & 3 & 0 & 0 & 15 & 1 & 0 & 0 & 0.719 \\
\hline \multicolumn{10}{|l|}{ Nonhematologic toxicity } \\
\hline Hand-foot syndrome & 3 & 0 & 0 & 0 & 1 & 0 & 0 & 0 & 0.620 \\
\hline Anorexia & 19 & 0 & 0 & 0 & 18 & 2 & 1 & 0 & 0.283 \\
\hline Vomiting & 6 & 6 & 0 & 0 & 14 & 8 & 2 & 0 & 0.010 \\
\hline Diarrhea & 5 & 2 & 0 & 0 & 6 & 2 & 1 & 0 & 0.860 \\
\hline Constipation & 1 & 0 & 0 & 0 & 3 & 0 & 0 & 0 & 0.339 \\
\hline Abdominal pain & 14 & 1 & 0 & 0 & 12 & 1 & 0 & 0 & 1.000 \\
\hline Stomatitis & 21 & 0 & 0 & 0 & 30 & 0 & 0 & 0 & 0.016 \\
\hline
\end{tabular}

Abbreviations: same as Table 1.

Some patients experienced more than one toxicity.

${ }^{*}$ National Cancer Institute Common Terminology Criteria for Adverse Events, version 3.0.

${ }^{\dagger}$ Fisher's exact test, two-tailed. 
Table 3 Tumor responses ${ }^{*}$ in the capecitabine and 5-fluorouracil (5-FU) groups

\begin{tabular}{|c|c|c|c|}
\hline Response & Capecitabine $\left(\mathrm{n}=51^{\dagger}\right), \mathrm{n}(\%)$ & 5 -FU (n= 46), n (\%) & $p$-value \\
\hline Primary tumor & & & $0.658^{\ddagger}$ \\
\hline Complete response & $0(0)$ & $0(0)$ & \\
\hline Partial response & $16(30.7)$ & $13(28.2)$ & \\
\hline Stable disease & $35(67.3)$ & $32(69.6)$ & \\
\hline Progressive disease & $0(0)$ & $1(2.2)$ & \\
\hline Overall & & & $0.273^{\ddagger}$ \\
\hline Complete response & $0(0)$ & $0(0)$ & \\
\hline Partial response & $7(13.7)$ & $7(15.2)$ & \\
\hline Stable disease & $10(19.6)$ & $15(32.6)$ & \\
\hline Progressive disease & $34(66.7)$ & $24(52.2)$ & \\
\hline \multicolumn{4}{|c|}{ CA 19-9 percent decrease (\%) } \\
\hline Median (range) & $38.9(-624.1-98.9)$ & $39.7(-383.4-98.6)$ & $0.484^{\S}$ \\
\hline Mean \pm SE & $-1.9 \pm 19.5$ & $16.2 \pm 15.8$ & \\
\hline$<40$ & $29(55.8)$ & $26(56.5)$ & $1.000^{\ddagger}$ \\
\hline$\geq 40$ & $23(44.2)$ & $20(43.5)$ & \\
\hline
\end{tabular}

"Response assessment in solid tumors (RECIST) version 1.1.

${ }^{\dagger} \mathrm{No}$ available radiologic image for one patient.

FFisher's exact test, two-tailed.

st-test, two-tailed.

negative and 2 margin positive. Rates of conversion to resectability were similar in the capecitabine and 5 -FU groups [4/52 (7.7\%) vs. $3 / 46(6.5 \%), p=1.000]$. Of the 7 resected patients, 2 developed locoregional recurrence, 3.5 and 5.5 months later, with the remaining 5 continuing to be locoregionally controlled. After completion of CRT, 47 patients (48\%), received gemcitabine based chemotherapy until disease progression, treatmentlimiting toxicity, or death; the median number of chemotherapy cycles was 3 (range, 1-17). The remaining 51 patients (52\%) did not receive maintenance chemotherapy because of patient refusal or poor performance status. The distribution of patients receiving maintenance chemotherapy were similar in the capecitabine and 5-FU groups [26/52 (50\%) vs. 21/46 (45.7\%), $p=0.667]$.

At the time of analysis, 96 patients (92.9\%) had died and $2(7.1 \%)$ remained alive. The median OS time for all patients was 12.1 months [95\% confidence interval (CI), 9.8-13.4 months] and the median OS times for the capecitabine and 5-FU groups were 12.5 months (95\% CI, 10.7-13.7 months)and 11.6 months $(95 \% \mathrm{CI}$, 8.513.8 months), respectively $(p=0.655)$ (Figure 1$)$. Table 4 summarizes the results of univariate analysis for the prognostic factors associated with OS. Maintenance chemotherapy (No vs. Yes) was significantly associated with OS $(10.6$ months vs. 14.4 months, $p<0.001)$ and $\mathrm{N}$ classification (N0 vs. N1; 13.0 months vs. 10.7 months, $p=0.069)$ and pretreatment CA 19-9 level (< 400vs. $\geq$ $400 \mathrm{U} / \mathrm{mL} ; 12.7$ months vs. 9.7 months, $p=0.063$ ) showed marginal associations with OS, whereas none of the other parameters was significantly associated with OS $(p>0.05)$ (Table 4). Multivariate analysis showed that pretreatment CA 19-9 level and maintenance chemotherapy were independent prognostic factors for OS $(p<0.05)$ (Table 5).

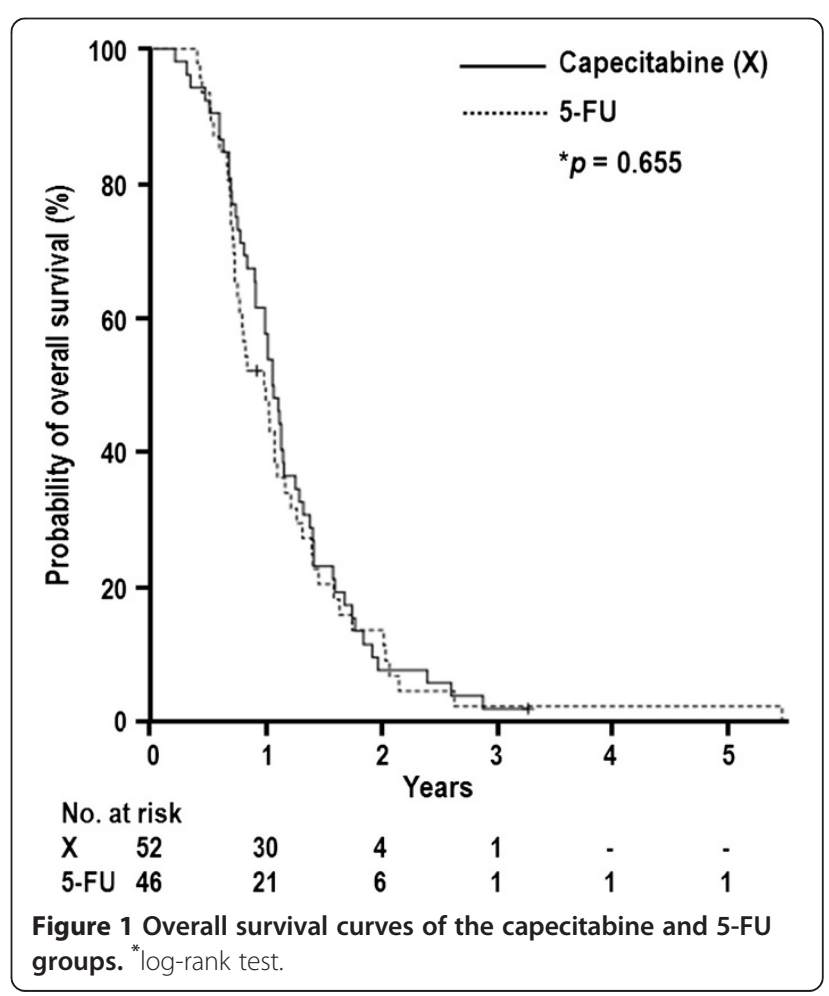


Table 4 Univariate analysis of factors influencing overall survival

\begin{tabular}{|c|c|c|c|}
\hline \multicolumn{4}{|c|}{$\begin{array}{ll}+2 & \text { Overall survival }\end{array}$} \\
\hline & & Median $(95 \% \mathrm{Cl})$, months & $p$-value ${ }^{*}$ \\
\hline \multirow[t]{2}{*}{ Gender } & Male & $11.6(9.2-14.0)$ & 0.426 \\
\hline & Female & $13.4(12.2-14.6)$ & \\
\hline \multirow[t]{2}{*}{ Age (years) } & $<65$ & $12.0(10.9-13.1)$ & 0.608 \\
\hline & $\geq 65$ & $12.1(9.8-14.4)$ & \\
\hline \multirow[t]{2}{*}{ Tumor location } & Head & $11.6(9.0-13.0)$ & 0.413 \\
\hline & Body/tail & $13.0(9.5-15.6)$ & \\
\hline \multirow[t]{2}{*}{ Tumor size $(\mathrm{cm})$} & $<4$ & $12.7(9.6-13.8)$ & 0.664 \\
\hline & $\geq 4$ & $12.0(9.3-13.4)$ & \\
\hline \multirow[t]{3}{*}{ Histological differentiation } & Well/moderate & $13.4(10.6-15.6)$ & 0.717 \\
\hline & Poor & $8.8(5.9-25.7)$ & \\
\hline & Not specified & $12.2(9.5-13.2)$ & \\
\hline \multirow[t]{2}{*}{ cN classification } & No & $13.0(10.6-15.0)$ & 0.069 \\
\hline & N1 & $10.7(8.8-12.7)$ & \\
\hline \multirow[t]{2}{*}{ CEA (ng/ mL) } & $<5$ & $12.6(9.8-13.4)$ & 0.190 \\
\hline & $\geq 5$ & $11.8(8.3-13.7)$ & \\
\hline \multirow[t]{2}{*}{ Pretreatment CA 19-9 level (U/mL) } & $<400$ & $12.7(11.6-15.0)$ & 0.063 \\
\hline & $\geq 400$ & $9.7(8.3-12.7)$ & \\
\hline \multirow[t]{2}{*}{ Concurrent chemotherapy } & Capecitabine & $12.5(10.7-13.7)$ & 0.655 \\
\hline & $5-\mathrm{FU}$ & $11.6(8.5-13.8)$ & \\
\hline \multirow[t]{2}{*}{ Primary tumor response } & Responder & $13.6(8.6-18.9)$ & 0.165 \\
\hline & Nonresponder & $11.9(9.6-13.0)$ & \\
\hline \multirow[t]{2}{*}{ CA 19-9 percent decrease (\%) } & $<40$ & $11.6(9.0-13.1)$ & 0.639 \\
\hline & $\geq 40$ & $12.7(10.7-14.4)$ & \\
\hline \multirow[t]{2}{*}{ Post-CRT surgery } & No & $12.2(9.8-13.4)$ & 0.883 \\
\hline & Yes & $12.0(5.9-25.7)$ & \\
\hline \multirow[t]{2}{*}{ Maintenance chemotherapy } & No & $10.6(8.5-12.1)$ & $<0.001$ \\
\hline & Yes & $14.4(11.7-18.8)$ & \\
\hline
\end{tabular}

Abbreviations: Responder complete or partial response, Nonresponder stable disease or progressive disease NS not significant, $p>0.05$, others are same as in Table 1.

*og rank test.

\section{Discussion}

We found that the rates of Grade $\geq 3$ hematologic $(0 \%$ vs. $8.7 \%, p=0.045)$ and non-hematologic ( $0 \%$ vs. $8.7 \%$, $p=0.045$ ) toxicities were significantly lower in the capecitabine group than in the 5-FU group. Lower toxicity rates may have been due to the pharmacodynamic advantages of oral capecitabine relative to bolus 5-FU [15]. Capecitabine is a tumor-selective fluoropyrimidine carbamate that is converted to active 5-FU by TP, an enzyme of higher abundance in tumor than in normal tissue that is upregulated by radiation in tumor but not in normal tissue $[9,10]$. Thus, theoretically, capecitabine could show lower rates of toxicity than bolus 5-FU. A previous study found that the rate of Grade $\geq 3$ hematologic toxicity was lower in patients receiving capecitabine than 5-FU during preoperative CRT for

Table 5 Multivariate analysis of factors influencing overall survival

\begin{tabular}{lcccr}
\hline Factor & & Hazard ratio & 95\% Cl & -value $^{*}$ \\
\hline CA 19-9 level $(\mathrm{U} / \mathrm{mL})$ & $<400$ & 1.000 & & $<0.001$ \\
& $\geq 400$ & 3.750 & $1.757-8.005$ & $<0.001$ \\
\hline Maintenance chemotherapy & No & 1.000 & $0.096-0.495$ & \\
\hline
\end{tabular}

Abbreviations: $\mathrm{Cl}$ confidence interval, other abbreviations are as in Table 1.

${ }^{*}$ Multivariate analysis using the Cox proportional hazards model. 
locally advanced rectal cancer ( $1.5 \%$ vs. $7.8 \%, p=0.04)$, similar to our results, but that rates of Grade $\geq 3$ diarrhea $(8.6 \%$ vs. $2.1 \%, p=0.006)$ and hand-foot syndrome $(2 \%$ vs. $0 \%, p=0.061$ ) were higher in the capecitabine group [16]. However, a phase II trial of induction chemotherapy with gemcitabine and cisplatin followed by CRT with capecitabine in patients with locally advanced pancreatic cancer showed that the rates of Grade $\geq 3$ diarrhea (5.4\%) and hand-foot syndrome (0\%) were low during CRT [17], similar to our findings. These findings implied that the lower rates of Grade $\geq 3$ nonhematologic toxicity in the capecitabine than in the 5FU group in our study maybe due to genetic differences in tolerability or susceptibility to capecitabine between Caucasians and Asians, as the conversion rate of tegafur to fluorouracil is different between Caucasians and Asians due to polymorphic differences in the CYP2A6 gene $[18,19]$. However, due to the relatively small number of patients in the capecitabine group $(n=52)$, which may be insufficient to determine the overall actual toxicity rates thoroughly and low incidence of toxicities in western study treated with CRT with capecitabine [20], more comprehensive and larger-scale studies should be needed.

Protracted infusion of 5-FU and capecitabine, which prolongs the exposure of non-cycling tumor cells to 5FU, may enhance cytotoxicity relative to bolus 5-FU. Protracted infusion of 5-FU or capecitabine during adjuvant CRT has been shown to improve relapse-free survival (RFS) and OS, compared with bolus 5-FU, in patients with rectal cancer $[16,21]$. In contrast, the Intergroup 0144 study, which compared different 5-FU based chemotherapeutic regimens in rectal cancer, found that protracted and bolus infusion of 5-FU yielded similar RFS and OS, and our previous report [22] showed that capecitabine and bolus 5-FU resulted in similar radiologic and pathologic tumor responses in patients receiving preoperative CRT for rectal cancer. However, to date, it has been remained unclear whether chemotherapeutic regimens, among a protracted infusion of 5FU, capecitabine, or bolus injection of 5-FU, can result in superior outcomes in patients with pancreatic cancer. We found that capecitabine, which mimics the protracted infusion of 5-FU, and bolus 5-FU yielded similar tumor responses and overall survival in patients with locally advanced pancreatic cancer.

A randomized trial found that, compared to5-FU, gemcitabine yielded better outcomes, including alleviation of disease-related symptoms and longer OS, in patients with advanced, symptomatic pancreatic cancer [23], and thus various dosages and schedules of gemcitabine based chemotherapy, with or without RT, have been tried to improve survival in locally advanced pancreatic cancer patients [4-6,8]. These studies, however, showed that gemcitabine based chemotherapy, with or without oxaliplatin, paclitaxel, docetaxel, and tyrosine kinase inhibitors, resulted in high rates of severe toxicities, without survival benefits, compared to 5-FU. Thus, 5-FU continues to be used as a concurrent chemotherapeutic agent during CRT [5]. To evaluate the effectiveness and safety of capecitabine, we compared outcomes, including toxicity, tumor response and overall survival, of RT plus capecitabine or bolus 5-FU, in patients with locally advanced pancreatic cancer.

This study was retrospective and thus had certain inherent limitations. First, it included relatively small numbers of patients in the capecitabine $(\mathrm{n}=52)$ and 5 -FU $(\mathrm{n}=46)$ groups, which may have been insufficient to compare outcomes thoroughly. Second, this was a retrospective comparison study of two groups with different chemotherapeutic regimens, not a randomized trial. Thus, further larger scaled and comprehensive studies are required to accurately compare the outcomes of these two chemotherapy regimens in patients with locally advanced pancreatic cancer. However, in present study, the characteristics of patients in the two groups did not differ significantly, and each chemotherapeutic regimen was decided according to patient's preferences.

\section{Conclusion}

In conclusion, we compared the outcomes of CRT with capecitabine or bolus 5-FU in patients with locally advanced pancreatic cancer. We found that CRT with capecitabine had low toxicity rates, but yielded similar tumor responses and overall survival compared with CRT with bolus 5-FU. These findings suggest that capecitabine may be a safe and feasible chemotherapy regimen in patients with locally advanced pancreatic cancer treated with CRT.

\section{Competing interests}

None of the authors have potential conflicts of interest.

\section{Authors' contributions}

THK, SMW, WJL and YJK are responsible for the study design. THK, WJL, SMW, YJK, TSK, SSH, BHK, SHM, SSK, YHK, SJP, DYK and JWP collected the clinical data and drafted the manuscript. THK, SMW, WJL, JK, DYK and YJK revised the manuscript. YJK, WJL and SMY collected the pathologic data and analysis THK, DYK, WJL and SMW were responsible for the treatment and evaluation of the patients. SJP, SHM, SSK, DYK, JWP and THK provided oversight of the analysis of data and reviewing of the manuscript. All authors read and approved the final manuscript.

\section{Acknowledgments}

This work was supported by a National Cancer Center Grant (NCC-1310080 1241110 and 1340940).

Received: 28 March 2013 Accepted: 28 June 2013 Published: 3 July 2013

\section{References}

1. A multi-institutional comparative trial of radiation therapy alone and in combination with 5-fluorouracil for locally unresectable pancreatic carcinoma. The Gastrointestinal Tumor Study Group. Ann Surg 1979, 189:205-208. 
2. Treatment of locally unresectable carcinoma of the pancreas: comparison of combined-modality therapy (chemotherapy plus radiotherapy) to chemotherapy alone. Gastrointestinal Tumor Study Group. J Natl Cancer Inst 1988, 80:751-755.

3. Moertel CG, Frytak S, Hahn RG, O'Connell MJ, Reitemeier RJ, Rubin J, Schutt AJ, Weiland LH, Childs DS, Holbrook MA, et al: Therapy of locally unresectable pancreatic carcinoma: a randomized comparison of high dose (6000 rads) radiation alone, moderate dose radiation (4000 rads + 5-fluorouracil), and high dose radiation + 5-fluorouracil: The Gastrointestinal Tumor Study Group. Cancer 1981, 48:1705-1710.

4. Huguet F, Girard N, Guerche CS, Hennequin C, Mornex F, Azria D: Chemoradiotherapy in the management of locally advanced pancreatic carcinoma: a qualitative systematic review. J Clin Oncol 2009, 27:2269-2277

5. Crane $\mathrm{CH}$, Abbruzzese JL, Evans DB, Wolff RA, Ballo MT, Delclos M, Milas L, Mason K, Charnsangavej C, Pisters PW, et al: Is the therapeutic index better with gemcitabine-based chemoradiation than with 5-fluorouracil-based chemoradiation in locally advanced pancreatic cancer? Int J Radiat Oncol Biol Phys 2002, 52:1293-1302

6. Wilkowski R, Boeck S, Ostermaier S, Sauer R, Herbst M, Fietkau R, Flentje M, Miethe S, Boettcher HD, Scholten T, et al: Chemoradiotherapy with concurrent gemcitabine and cisplatin with or without sequential chemotherapy with gemcitabine/cisplatin vs chemoradiotherapy with concurrent 5-fluorouracil in patients with locally advanced pancreatic cancer-a multi-centre randomised phase II stud. Br J Cancer 2009, 101:1853-1859.

7. Ben-Josef E, Shields AF, Vaishampayan U, Vaitkevicius V, El-Rayes BF, McDermott P, Burmeister J, Bossenberger T, Philip PA: Intensity-modulated radiotherapy (IMRT) and concurrent capecitabine for pancreatic cancer. Int J Radiat Oncol Biol Phys 2004, 59:454-459.

8. McGinn CJ, Zalupski MM, Shureiqi I, Robertson JM, Eckhauser FE, Smith DC, Brown D, Hejna G, Strawderman M, Normolle D, Lawrence TS: Phase I trial of radiation dose escalation with concurrent weekly full-dose gemcitabine in patients with advanced pancreatic cancer. J Clin Oncol 2001, 19:4202-4208.

9. Miwa M, Ura M, Nishida M, Sawada N, Ishikawa T, Mori K, Shimma N, Umeda I, Ishitsuka H: Design of a novel oral fluoropyrimidine carbamate, capecitabine, which generates 5 -fluorouracil selectively in tumours by enzymes concentrated in human liver and cancer tissue. Eur J Cancer 1998, 34:1274-1281.

10. Sawada N, Ishikawa $T$, Sekiguchi $F$, Tanaka $Y$, Ishitsuka H: X-ray irradiation induces thymidine phosphorylase and enhances the efficacy of capecitabine (Xeloda) in human cancer xenografts. Clin Cancer Res 1999, 5:2948-2953.

11. Roche CJ, Hughes ML, Garvey CJ, Campbell F, White DA, Jones L, Neoptolemos JP: CT and pathologic assessment of prospective nodal staging in patients with ductal adenocarcinoma of the head of the pancreas. AJR Am J Roentgenol 2003, 180:475-480.

12. Therasse P, Arbuck SG, Eisenhauer EA, Wanders J, Kaplan RS, Rubinstein L, Verweij J, Van Glabbeke M, van Oosterom AT, Christian MC, Gwyther SG: New guidelines to evaluate the response to treatment in solid tumors. European Organization for Research and Treatment of Cancer, National Cancer Institute of the United States, National Cancer Institute of Canada. J Natl Cancer Inst 2000, 92:205-216.

13. Yoo T, Lee WJ, Woo SM, Kim TH, Han SS, Park SJ, Moon SH, Shin KH, Kim SS, Hong EK, et al: Pretreatment carbohydrate antigen 19-9 level indicates tumor response, early distant metastasis, overall survival, and therapeutic selection in localized and unresectable pancreatic cancer. Int J Radiat Oncol Biol Phys 2011, 81:e623-e630.

14. Kim TH, Han SS, Park SJ, Lee WJ, Woo SM, Yoo T, Moon SH, Kim SH, Hong EK, Kim DY, Park JW: CA 19-9 level as indicator of early distant metastasis and therapeutic selection in resected pancreatic cancer. Int J Radiat Oncol Biol Phys 2011, 81:e743-e748.

15. Schuller J, Cassidy J, Dumont E, Roos B, Durston S, Banken L, Utoh M, Mori K, Weidekamm E, Reigner B: Preferential activation of capecitabine in tumor following oral administration to colorectal cancer patients. Cancer Chemother Pharmacol 2000, 45:291-297.

16. Hofheinz RD, Wenz F, Post S, Matzdorff A, Laechelt S, Hartmann JT, Muller L,

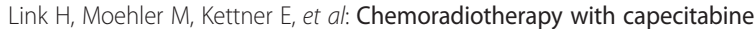
versus fluorouracil for locally advanced rectal cancer: a randomised, multicentre, non-inferiority, phase 3 trial. Lancet Oncol 2012, 13:579-588.
17. Kim JS, Lim JH, Kim JH, Im SA, Chie EK, Hwang JH, Kim TY, Bang YJ, Ha SW, Yoon YB: Phase II clinical trial of induction chemotherapy with fixed dose rate gemcitabine and cisplatin followed by concurrent chemoradiotherapy with capecitabine for locally advanced pancreatic cancer. Cancer Chemother Pharmacol 2012, 70:381-389.

18. Ohtsu A, Yoshida S, Saijo N: Disparities in gastric cancer chemotherapy between the East and West. J Clin Oncol 2006, 24:2188-2196.

19. Ajani JA, Faust J, Ikeda K, Yao JC, Anbe H, Carr KL, Houghton M, Urrea P. Phase I pharmacokinetic study of S-1 plus cisplatin in patients with advanced gastric carcinoma. J Clin Oncol 2005, 23:6957-6965.

20. Mukherjee S, Hurt CN, Bridgewater J, Falk S, Cummins S, Wasan H, Crosby T, Jephcott C, Roy R, Radhakrishna G, et al: Gemcitabine-based or capecitabine-based chemoradiotherapy for locally advanced pancreatic cancer (SCALOP): a multicentre, randomised, phase 2 trial. Lancet Oncol 2013, 14:317-326.

21. O'Connell MJ, Martenson JA, Wieand HS, Krook JE, Macdonald JS, Haller DG, Mayer RJ, Gunderson LL, Rich TA: Improving adjuvant therapy for rectal cancer by combining protracted-infusion fluorouracil with radiation therapy after curative surgery. N Engl J Med 1994, 331:502-507.

22. Kim DY, Jung KH, Kim TH, Kim DW, Chang HJ, Jeong JY, Kim YH, Son SH, Yun T, Hong CW, et al: Comparison of 5-fluorouracil/leucovorin and capecitabine in preoperative chemoradiotherapy for locally advanced rectal cancer. Int J Radiat Oncol Biol Phys 2007, 67:378-384.

23. Burris HA 3rd, Moore MJ, Andersen J, Green MR, Rothenberg ML, Modiano MR, Cripps MC, Portenoy RK, Storniolo AM, Tarassoff P, et al: Improvements in survival and clinical benefit with gemcitabine as first-line therapy for patients with advanced pancreas cancer: a randomized trial. J Clin Oncol 1997, 15:2403-2413.

doi:10.1186/1748-717X-8-160

Cite this article as: Kim et al:: Comparison of capecitabine and 5fluorouracil in chemoradiotherapy for locally advanced pancreatic cancer. Radiation Oncology 2013 8:160.

\section{Submit your next manuscript to BioMed Central and take full advantage of:}

- Convenient online submission

- Thorough peer review

- No space constraints or color figure charges

- Immediate publication on acceptance

- Inclusion in PubMed, CAS, Scopus and Google Scholar

- Research which is freely available for redistribution

Submit your manuscript at www.biomedcentral.com/submit
C) BioMed Central 